Supporting Information

\title{
Complete Degradation of a Conjugated Polymer into Green Upcycling Products by Sunlight in Air
}

Sidan Tian ${ }^{a \dagger}$, Qiang Yue ${ }^{a \dagger}$, Chenchen Liu ${ }^{b}$, Mengyang Li ${ }^{a}$, Mingming Yin ${ }^{a}$, Yuting Gao , Fanling Meng ${ }^{a}$, Ben Zhong Tang ${ }^{b, c *}$, Liang Luo ${ }^{a, d *}$

a. National Engineering Research Center for Nanomedicine, College of Life Science and Technology, Huazhong University of Science and Technology, Wuhan 430074, China

b. Department of Chemistry and Hong Kong Branch of Chinese National Engineering Research Center for Tissue Restoration and Reconstruction, The Hong Kong University of Science \& Technology, Clear Water Bay, Kowloon, Hong Kong 999077, P. R. China

c. Shenzhen Institute of Molecular Aggregate Science and Engineering, School of Science and Engineering, The Chinese University of Hong Kong, Shenzhen 518172, China

d. Hubei Key Laboratory of Bioinorganic Chemistry and Materia Medica, School of Chemistry and Chemical Engineering, Huazhong University of Science and Technology, Wuhan, 430074 China 


\section{Table of Contents}

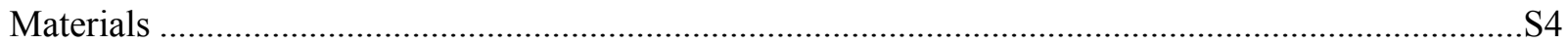

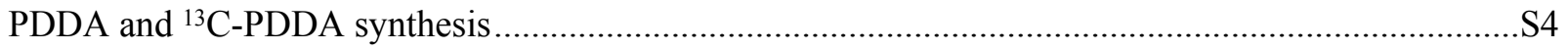

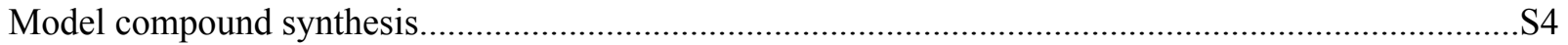

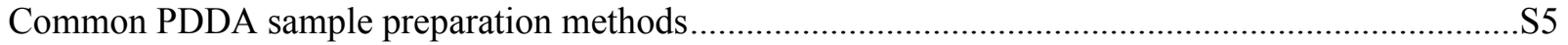

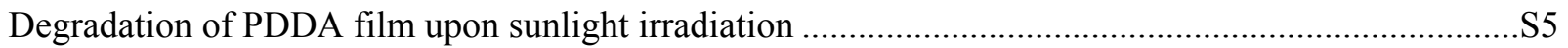

Degradation and spectral analysis of aqueous PDDA dispersion upon sunlight irradiation ...................S5

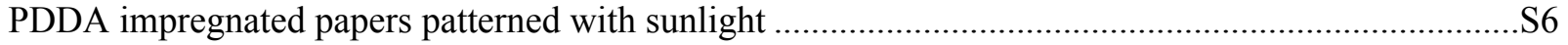

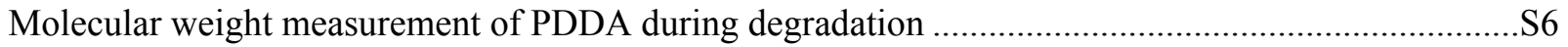

Viscosity measurement of PDDA solution during degradation measurement .....................................S7

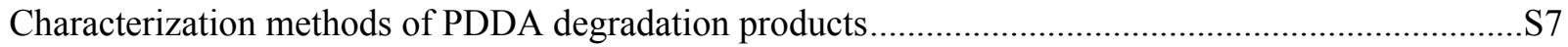

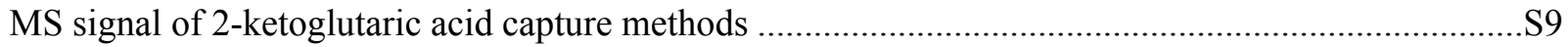

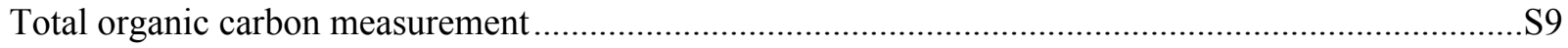

Characterization methods of model compound degradation products.................................................S10

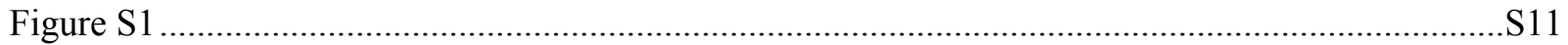

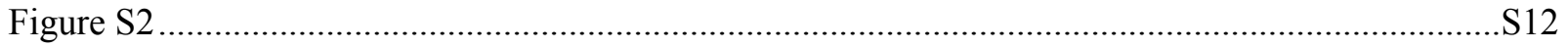

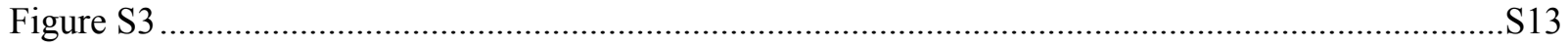

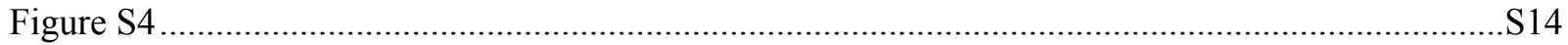

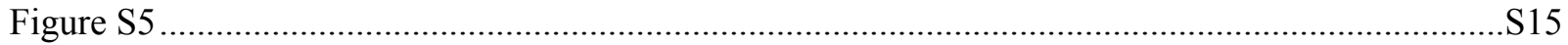

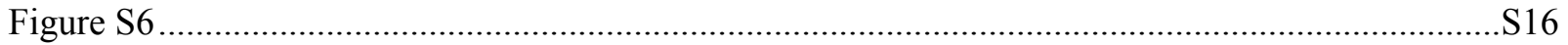

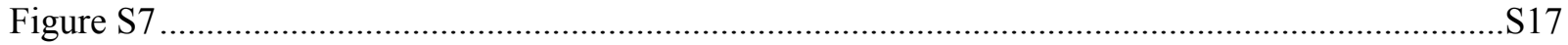

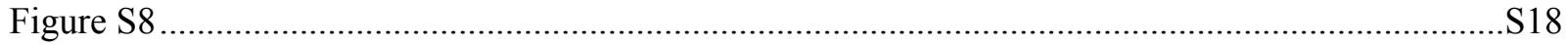

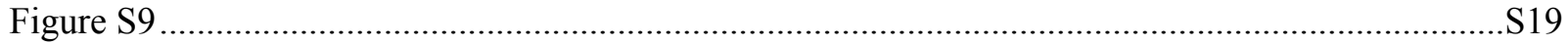

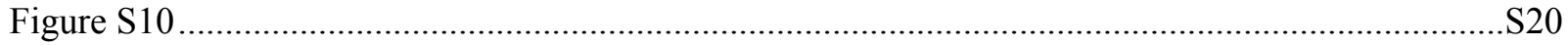

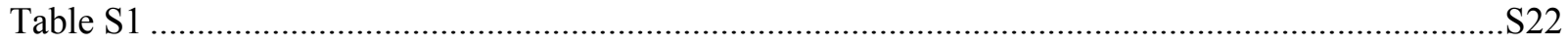

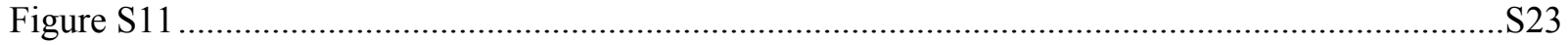

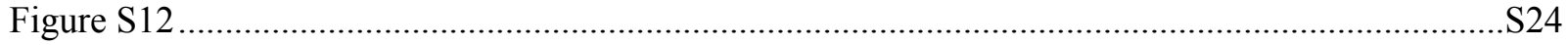

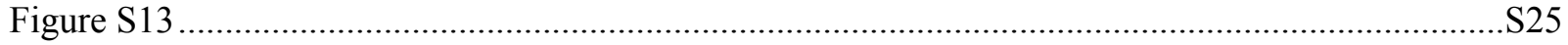

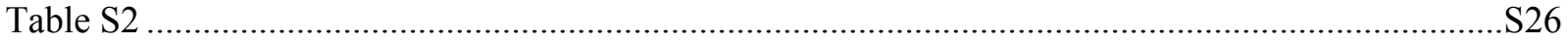

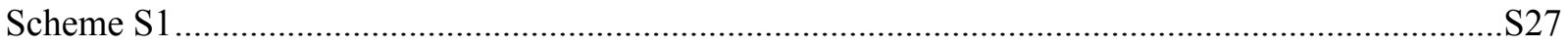

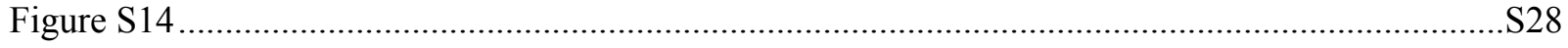

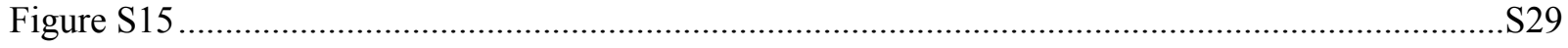

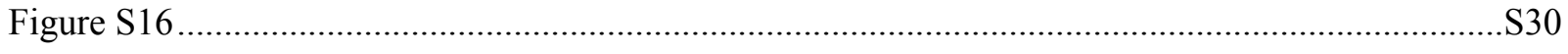

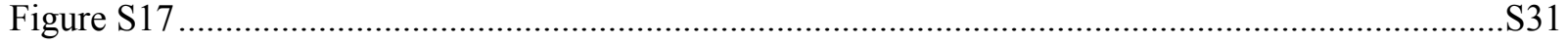




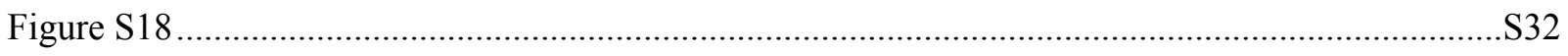

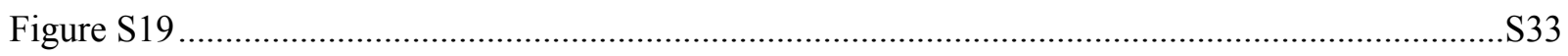

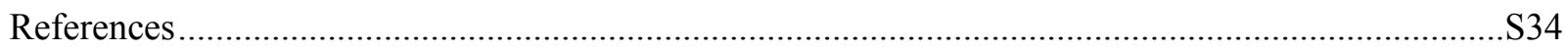




\section{Materials}

Sodium hydroxide $(\mathrm{NaOH})$, hydrochloric acid $(\mathrm{HCl})$, sodium chloride $(\mathrm{NaCl})$, acetic acid, and formic acid were purchased from Sinopharm Chemical Reagent Co. Ltd. Propanedioic acid, malic acid and succinic acid (SA) were purchased from Shanghai Aladdin Bio-Chem Technology Co., Ltd. 2-hydroxyglutaric acid was purchased from Shanghai Haohong Scientific Co., Ltd. $\mathrm{Fe}_{3} \mathrm{O}_{4}$ nanoparticles were purchased from Rhawn Chemical. Deuterated solvents were purchased from Cambridge Isotope Laboratories, Inc. Chromatographic grade acetonitrile was purchased from Fisher Chemicals. (Trimethylsilyl)acetylene- ${ }^{13} \mathrm{C}_{2}$ were purchased from Sigma-Aldrich (Shanghai) Trading Co.,Ltd. All reagents in the organic synthesis, 4-pentyn-1-ol, methylene blue (MB) and Rose Bengal (RB) were purchased from Energy Chemical. All other reagents and solvents were purchased from Sinopharm Chemical Reagent Co. Ltd. and used as received.

\section{PDDA and ${ }^{13}$ C-PDDA synthesis}

PDDA was synthesized from 4-pentyn-1-ol according to our previously reported procedures. ${ }^{1}$ For the synthesis of ${ }^{13} \mathrm{C}$-PDDA, (trimethylsilyl)acetylene- ${ }^{13} \mathrm{C}_{2}$ were used as the starting material to generate the 4-pentyn-1-ol- ${ }^{13} \mathrm{C}_{2}$ following literature procedures. ${ }^{2}{ }^{1} \mathrm{H} \mathrm{NMR}\left(400 \mathrm{MHz}, \mathrm{D}_{2} \mathrm{O}\right) \delta 2.43$ $(\mathrm{t}, J=7.2 \mathrm{~Hz}, 4 \mathrm{H}), 2.39(\mathrm{t}, J=7.2 \mathrm{~Hz}, 4 \mathrm{H})\left(\right.$ Figure S14). ${ }^{13} \mathrm{C} \mathrm{NMR}\left(100 \mathrm{MHz}, \mathrm{D}_{2} \mathrm{O}\right) \delta 63-66(\mathrm{~m}$, $2{ }^{13} \mathrm{C}$ ), 76-79 (m, $2{ }^{13} \mathrm{C}$ ) (Figure S15). HRMS $[\mathrm{M}-\mathrm{H}]^{-}: \mathrm{m} / \mathrm{z}$ calcd for $\mathrm{C}_{6}{ }^{13} \mathrm{C}_{4} \mathrm{H}_{9} \mathrm{O}_{4}^{-}, 197.0641$; found: 197.0635 (Figure S16).

\section{Model compound synthesis}


Synthesis of the model compound 4-phenylpent-4-enoic acid was referred to literature. ${ }^{3}{ }^{1} \mathrm{H}$ NMR (400 MHz, CDCl3) $\delta$ 7.40-7.10 (m, 5H), $5.39(\mathrm{~s}, 1 \mathrm{H}), 5.30(\mathrm{~s}, 1 \mathrm{H}), 2.61(\mathrm{t}, 2 \mathrm{H}), 2.52(\mathrm{t}, 2 \mathrm{H})$, consistent with the literature.

\section{Common PDDA sample preparation methods}

PDDA aqueous solution preparation: $5 \mathrm{mg}$ of PDDA was added to $2.5 \mathrm{~mL}$ of $\mathrm{NaOH}$ aqueous solution $(0.025 \mathrm{M})$ and stirred at room temperature until completely dissolved.

Aqueous PDDA particles dispersion preparation: $\mathrm{HCl}(1 \mathrm{M})$ was added into the stirring PDDA aqueous solution until small PDDA particles were precipitated.

PDDA film preparation: The aqueous PDDA dispersion was filtered at reduced pressure with a nylon filter film ( $0.22 \mu \mathrm{m}$ pores). The filter film was washed with deionized water to remove the residual salt, moistened with methanol and dried in the air. When the PDDA-attached nylon filter film was soaked in methanol, the PDDA film immediately fell off from the nylon filter, and further dried with a vacuum drying oven at room temperature for 2 hours.

\section{Degradation of PDDA film upon sunlight irradiation}

A PDDA film ( $1 \mathrm{mg}, \sim 2 \mathrm{~cm}$ in diameter) was placed in $10 \mathrm{ml}$ of deionized water or seawater in a covered vial. The vial was placed on an outdoor shelf in Wuhan, China $\left(30^{\circ} 29^{\prime} 13^{\prime \prime} \mathrm{N}, 114^{\circ} 28^{\prime} 13^{\prime \prime} \mathrm{E}\right)$ and left for seven whole days (days and nights).

\section{Degradation and spectral analysis of aqueous PDDA dispersion upon sunlight irradiation}

$20 \mathrm{~mL}$ of aqueous PDDA dispersion $(5 \mu \mathrm{g} \mathrm{mL}-1)$ was placed in a vial without lid exposed to sunlight irradiation on an outdoor shelf in Wuhan for $30 \mathrm{~min} .2 \mathrm{~mL}$ of the dispersion fluid was 
taken out each time upon different duration time of sunlight irradiation for photographing and UVvis spectra measurement, which was conducted on a TUS5 1810DSPC UV/Vis spectrophotometer (Puxi. General Instrumental Company, China). The PDDA dispersion samples with different irradiation time were added with $\mathrm{NaOH}$ to form a homogeneous solution. The as prepared solution sample was charged into a quartz tube of $5 \mathrm{~mm}$ diameter and $1 \mathrm{~mm}$ thickness. The tube was placed at a fixed relative position to the lens for quantitative Raman spectra analysis (Princeton Instruments Acton series SP-2500, with a liquid nitrogen cooled CCD camera Princeton Instruments PyLoN-100BR-eXcelon). A Sapphire SF $488 \mathrm{~nm}$ laser is applied to the sample with $5 \mathrm{~mW}$ laser power. The spectra were taken with integration time fixed at $0.5 \mathrm{~s}$. Each spectrum was accumulated for 10 times.

\section{PDDA impregnated papers patterned with sunlight}

Filter paper $(7 \times 2.5 \mathrm{~cm})$ was soaked in a PDDA solution $\left(2 \mathrm{mg} \mathrm{mL}^{-1}\right)$ for 30 minutes, and then naturally dried. The filter paper was repeatedly soaked and dried for 5 times. The filter paper was then soaked in $1 \%(\mathrm{v} / \mathrm{v})$ hydrochloric acid solution for 1 hour until the color of PDDA turned to red, and then dried naturally again. The dry filter paper was finally clamped using glass plates together with a mask made of tin foil, and then exposed to sunlight irradiation for 6 hours.

\section{Molecular weight measurement of PDDA during degradation}

$10 \mathrm{~mL}$ of an aqueous PDDA dispersion $\left(200 \mu \mathrm{g} \mathrm{mL}^{-1}\right)$ was illuminated by a simulated sunlight (white light, $5 \mathrm{~mW} \mathrm{~cm}{ }^{-2}$ ). After different duration time of simulation sunlight irradiation, $250 \mu \mathrm{L}$ of the dispersion was taken out and lyophilized, then re-dissolved with $50 \mu \mathrm{L}$ of $0.1 \mathrm{M} \mathrm{NaOH}$ as electrophoresis samples. 
Agarose gel electrophoresis (AGE): AGE is conducted with a DYCP-31DN horizontal electrophoresis apparatus (Beijing Liuyi Biotechnology Co., Ltd.). 3.5\% (w/w) agarose gel containing a nucleic acid dye Gelred (Biosharp Co., Ltd.), $150 \mathrm{~V}$ voltage and 45 min conduction time were used for the electrophoresis. DNA marker D2000 Plus (molecular weight ranges from $650 \mathrm{kDa}$ to $65 \mathrm{kDa}$, GenStar Biosolutions Co., Ltd.) and $10 \mathrm{bp}$ DNA Ladder (molecular weight ranges from $97.5 \mathrm{kDa}$ to $6.5 \mathrm{kDa}$, Thermo Fisher Scientific, USA) were employed for calibration. After the electrophoresis, the agarose gel was first submitted to fluorescence imaging using ChemiDoc XRS + System (Bio-Rad, USA), and then soaked in 1\% hydrochloric acid solution for 1 hour until the color of PDDA bands turned to red for photographing. The color intensity of PDDA bands were extracted using ImageJ $1.51 \mathrm{~J} 8$.

\section{Viscosity measurement of PDDA solution during degradation measurement}

$5 \mathrm{~mL}$ of an aqueous PDDA dispersion $\left(5 \mathrm{mg} \mathrm{mL}^{-1}\right)$ was exposed to sunlight irradiation for 10 days. Then, $\mathrm{NaOH}$ was added until the $\mathrm{pH}$ value of the dispersion reached to $8-10$. The shear viscosity of the PDDA solution and corresponding degradation product were measured with a Malvern Rotational Rheometer. The test was conducted under a shear frequency of $1 \mathrm{~Hz}$ with a flat rotator. Sample loading volume was fixed at $1 \mathrm{~mL}$. The PDDA solutions at different concentrations before or after degradation were tested under the same condition at $25^{\circ} \mathrm{C}$. The plot of shear viscosity versus concentration of PDDA solution before and after degradation was used for the evaluation of the viscosity change.

\section{Characterization methods of PDDA degradation products}


Degradation upon sunlight irradiation: $2.5 \mathrm{~mL}$ of aqueous PDDA dispersion $(2 \mathrm{mg} \mathrm{mL}-1)$ was exposed to sunlight irradiation for 4 days. $\mathrm{NaOH}$ was added to the dispersion until the $\mathrm{pH}$ value reached $8-10$. The dispersion was then lyophilized into degradation products.

Degradation upon methylene blue (MB) and red light irradiation: $2.5 \mathrm{~mL}$ of PDDA solution (2 $\mathrm{mg} \mathrm{mL} \mathrm{mL}^{-1}$ ) was exposed to LED red light irradiation $\left(640 \mathrm{~nm}, 5 \mathrm{~mW} \mathrm{~cm}{ }^{-2}\right)$ for 96 hours, $20 \mu 1 \mathrm{MB}$ aqueous solution (1.67 $\mathrm{mg} \mathrm{mL}^{-1}$ ) was added every 12 hours. The mixture was exposed to red light for another 24 hours. $\mathrm{NaOH}$ was added to the solution until the $\mathrm{pH}$ value reached $8-10$. The solution was then lyophilized into degradation products.

Degradation upon Rose Bengal (RB) and green light irradiation: $2.5 \mathrm{~mL}$ of a PDDA solution (2 $\mathrm{mg} \mathrm{mL}^{-1}$ ) was exposed to LED green light irradiation $\left(520 \mathrm{~nm}, 5 \mathrm{~mW} \mathrm{~cm}^{-2}\right)$ for 48 hours, in which $20 \mu \mathrm{L}$ of a $\mathrm{RB}$ aqueous solution $\left(2.5 \mathrm{mg} \mathrm{mL}^{-1}\right)$ was added every 12 hours. The solution was exposed to green light for another 24 hours. $\mathrm{NaOH}$ was added to the solution until the $\mathrm{pH}$ value reached $8-10$. The solution was then lyophilized into degradation products.

Degradation upon Fenton reaction: $5 \mathrm{mg}$ of $\mathrm{Fe}_{3} \mathrm{O}_{4}$ nanoparticles (20 $\mathrm{nm}$ particle size, Rhawn Chemical) was added to an aqueous PDDA dispersion $\left(5 \mathrm{~mL}, 1 \mathrm{mg} \mathrm{mL}^{-1}\right)$, and diluted hydrochloric acid was added to adjust the $\mathrm{pH}$ value to 4 . After stirring and dispersing, $100 \mu \mathrm{L}$ of $30 \%(\mathrm{w} / \mathrm{w}) \mathrm{H}_{2} \mathrm{O}_{2}$ was added every $12 \mathrm{~h}$ and stirred at room temperature for $48 \mathrm{~h}$. The reaction was terminated after another 24 hours. Reaction mixture was filtered to remove $\mathrm{Fe}_{3} \mathrm{O}_{4}$ nanoparticles through a $0.22 \mu$ m nylon filter film. The filtrate was added with $\mathrm{NaOH}$ until the $\mathrm{pH}$ value reached 12, and lyophilized into degradation products.

Each lyophilized degradation product was dissolved in $450 \mu \mathrm{L}$ of deuterium water for ${ }^{1} \mathrm{H}$ NMR (400 MHz) and ${ }^{13} \mathrm{C}$ NMR (400 MHz) measurement (Agilent 400-MR $400 \mathrm{MHz}$ ). 
High resolution mass spectroscopy (HR-MS) and high-performance liquid chromatography-mass spectrometry (HPLC-MS) were conducted on an Orbitrap LC/MS (Q Exactive) (Thermo Fisher Scientific, USA) with an electrospray interface, a Q Exactive mass analyser and an ion detector working in negative ion mode $\left(\mathrm{M}^{-}\right)$and an Ultimate 3000 UPLC system with a mass detector. HPLC-MS analysis used a C18 reverse-phase column (Welchrom ${ }^{\circledR} \mathrm{C} 184.6 \times 250 \mathrm{~mm}, 5 \mu \mathrm{m}$, Welch Technology Co., Ltd). The mobile phase consisted of acetonitrile and $0.1 \%$ formic acid in deionized water, and the ratio was 4:96 (0-25 $\mathrm{min})$, then slowly rose to 90:10 (25-40 $\mathrm{min})$ and finally stayed at 90:10 (40-50 min). The flow rate was $0.5 \mathrm{~mL} \mathrm{~min}^{-1}$, the sample was $10-200 \mu \mathrm{g}$ $\mathrm{mL}^{-1}$, the injection volume was $0.1-20 \mu \mathrm{L}$, negative mode ion signal intensity (total ion count, $\mathrm{M}^{-}$) was recorded.

\section{MS signal of 2-ketoglutaric acid capture methods}

$1 \mathrm{~mL}$ of an aqueous PDDA dispersion $\left(20 \mu \mathrm{g} \mathrm{mL}^{-1}\right)$ was placed in a covered vial and exposed to sunlight irradiation for 5 hours until the PDDA solid disappeared completely and the dispersion fluid became colorless. The mixture was submitted immediately to HPLC-MS analysis (Orbitrap LC/MS, Thermo Fisher Scientific, USA) with an electrospray interface, a Q Exactive mass analyzer, an ion detector working in negative ion mode, and an Ultimate 3000 UPLC system with a PDA detector. C18 reverse-phase column was used (Welchrom ${ }^{\circledR} \mathrm{C} 184.6 \times 250 \mathrm{~mm}, 5 \mu \mathrm{m}$, Welch Technology Co., Ltd). Mobile phase: Acetonitrile and $0.1 \%$ formic acid in deionized water

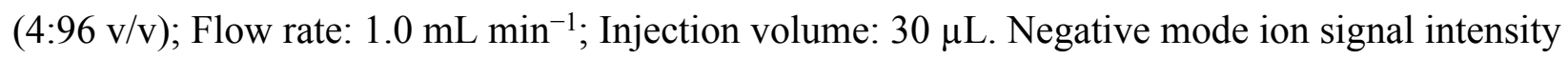
(ion count of $145.0132\left(\mathrm{M}^{-}\right)$) was recorded.

\section{Total organic carbon measurement}


$50 \mathrm{~mL}$ of an aqueous PDDA dispersion $\left(20 \mu \mathrm{g} \mathrm{mL}^{-1}\right)$ was placed in a covered vial exposed to sunlight irradiation for 6 hours until the PDDA solid completely disappeared and the dispersion became colorless. Total organic carbon measurements were conducted with three replicates on a Shimadzu TOC-L Laboratory Total Organic Carbon Analyzer. Pristine PDDA aqueous solution $\left(20 \mu \mathrm{g} \mathrm{mL}^{-1}\right.$ ) was also tested as a control. The $\mathrm{pH}$ values of all samples were set to 8 prior to the test.

\section{Characterization methods of model compound degradation products}

Degradation upon sunlight irradiation: $2.5 \mathrm{~mL}$ of the aqueous dispersion of 4-phenylpent-4-enoic acid $\left(2 \mathrm{mg} \mathrm{mL}^{-1}\right)$ was exposed to sunlight irradiation for 21 days. Then, added $\mathrm{NaOH}$ solution to adjust the $\mathrm{pH}$ to $8-10$, to change carboxylic acid organic products into carboxylic salts, and lyophilized into degradation products.

Lyophilized degradation products were dissolved in $450 \mu 1$ deuterium water for ${ }^{1} \mathrm{H}$ NMR (400 MHz) spectrum test conducted on an Agilent 400-MR $400 \mathrm{MHz}$ spectrometer operated in the Fourier transform mode.

HR-MS were conducted on an Orbitrap LC/MS (Q Exactive) (Thermo Fisher Scientific, USA) with an electrospray interface working in negative ion mode. 
A

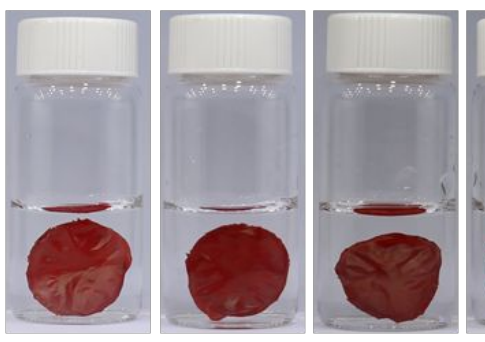

B

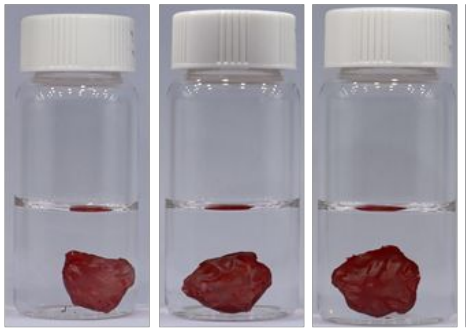

C

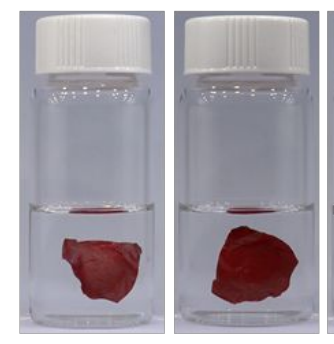

D

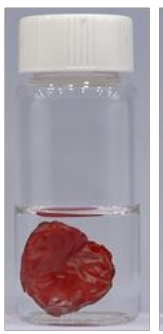

0

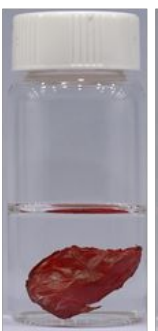

1
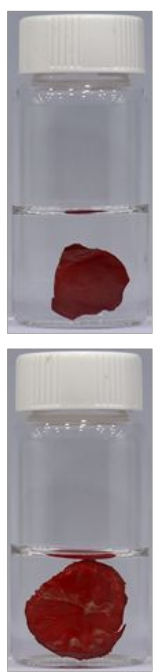

2
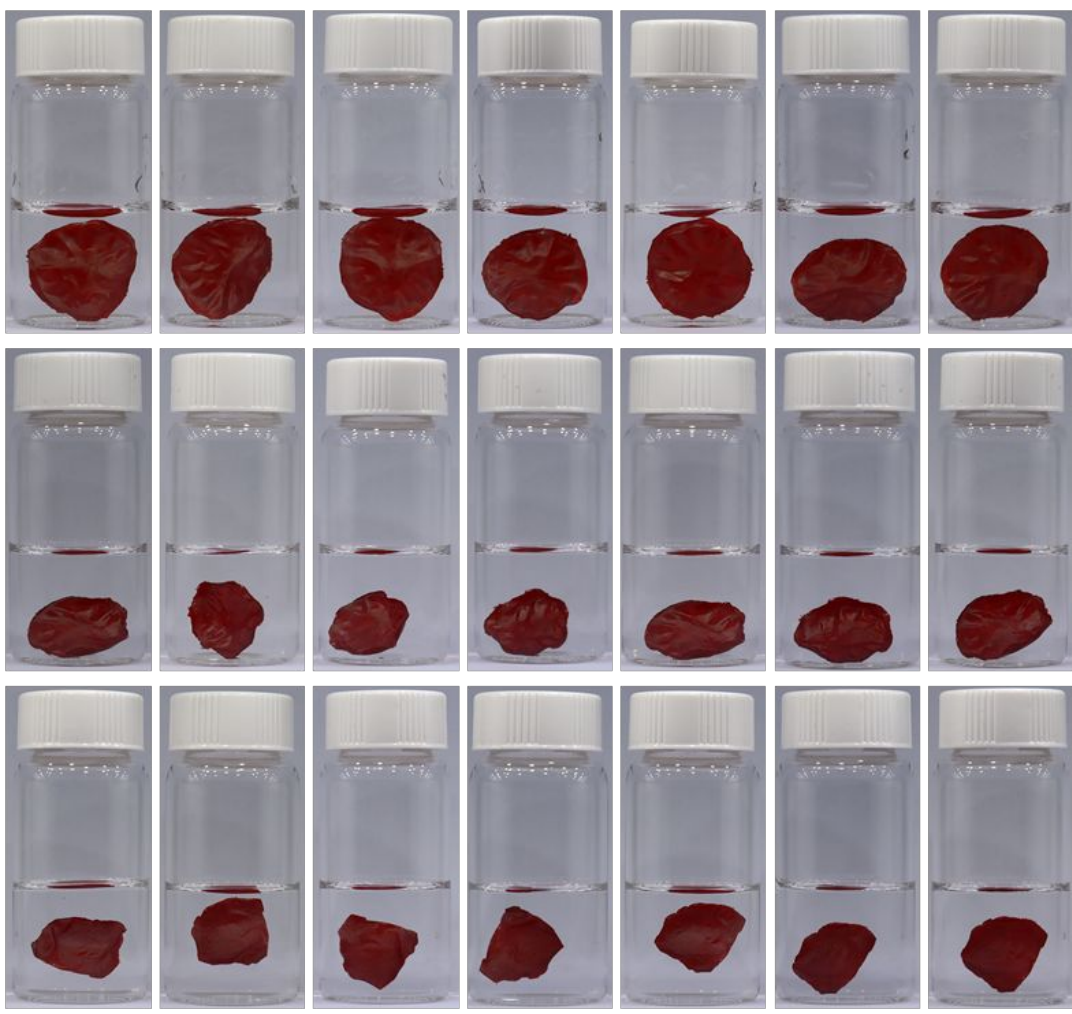

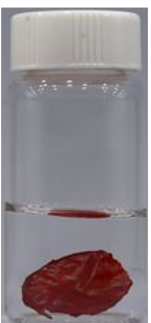

3

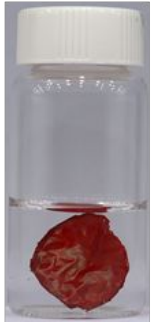

4

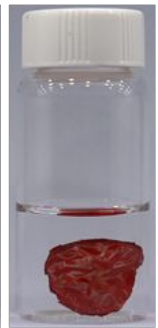

5

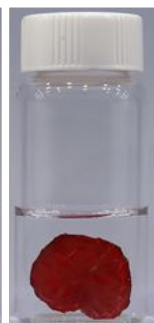

6

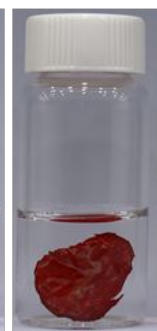

7

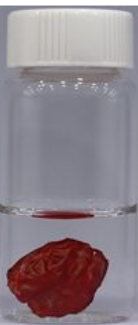

10

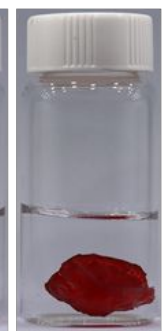

14

Figure S1. Photographs of PDDA films in different media being kept in the dark for different time.

(A) Weak acidic condition (pH 5); (B) Acetone; (C) Dichloromethane; (D) Hexane. 

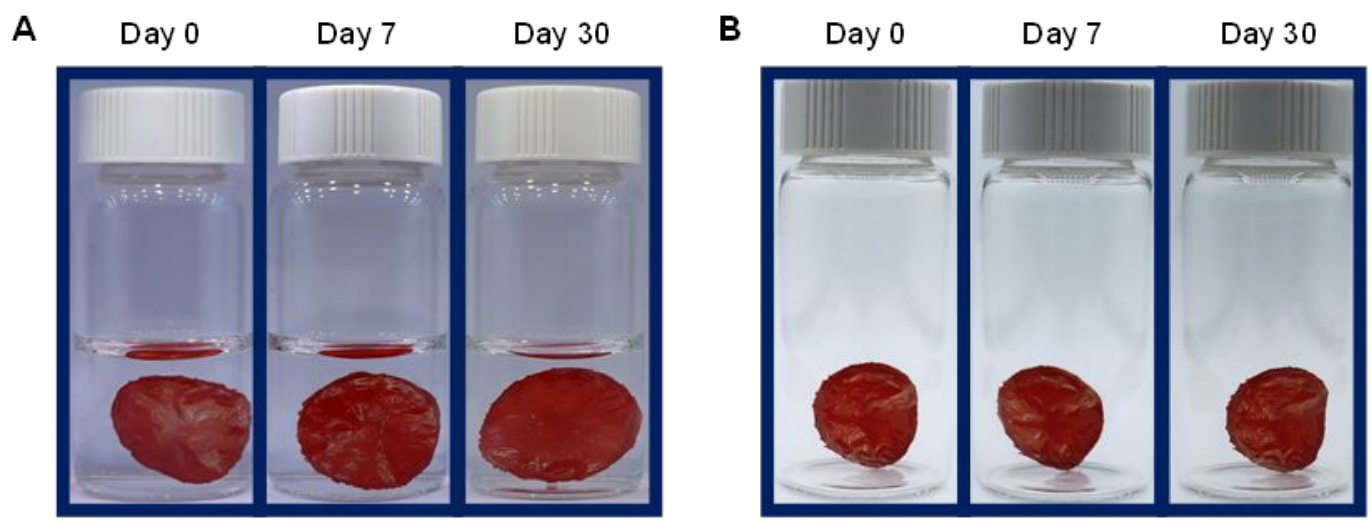

Figure S2. (A) Photographs of a PDDA film in deionized water being kept in the dark for different time. (B) Photographs of a PDDA film sealed in nitrogen atmosphere being exposed to sunlight for different time. 

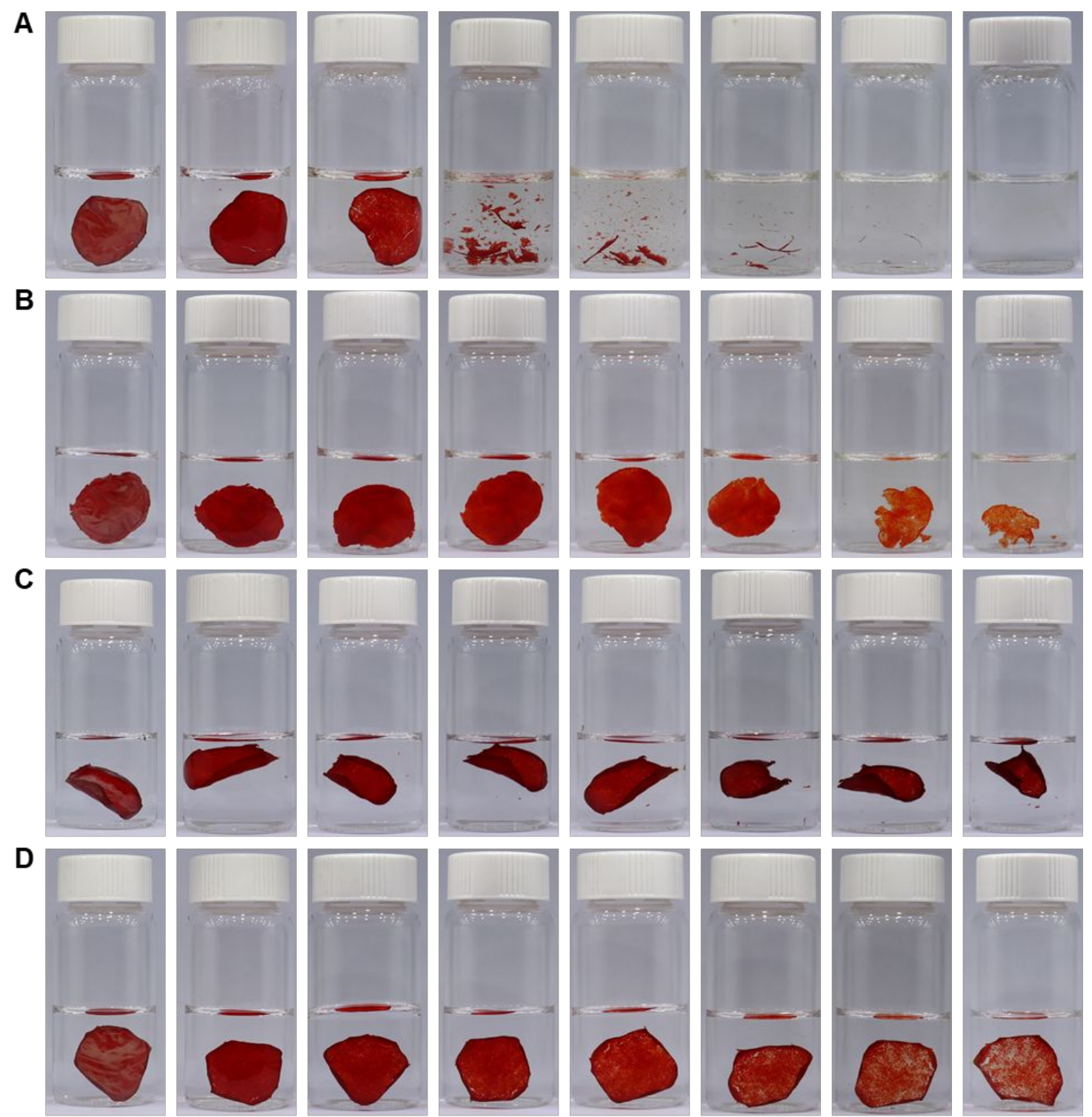

5
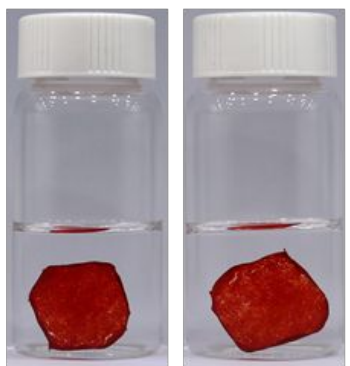

25
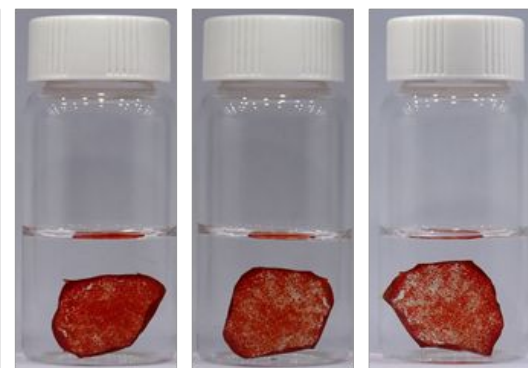

15

35

60

90

Irradiation Time (h)

Figure S3. Photographs of PDDA films in different media being exposed to light irradiation (white

light, $5 \mathrm{~mW} \mathrm{~cm} \mathrm{~cm}^{-2}$ ) for different time. (A) Weak acidic condition ( $\mathrm{pH} \mathrm{5.0);} \mathrm{(B)} \mathrm{Acetone;} \mathrm{(C)}$

Dichloromethane; (D) Hexane. 


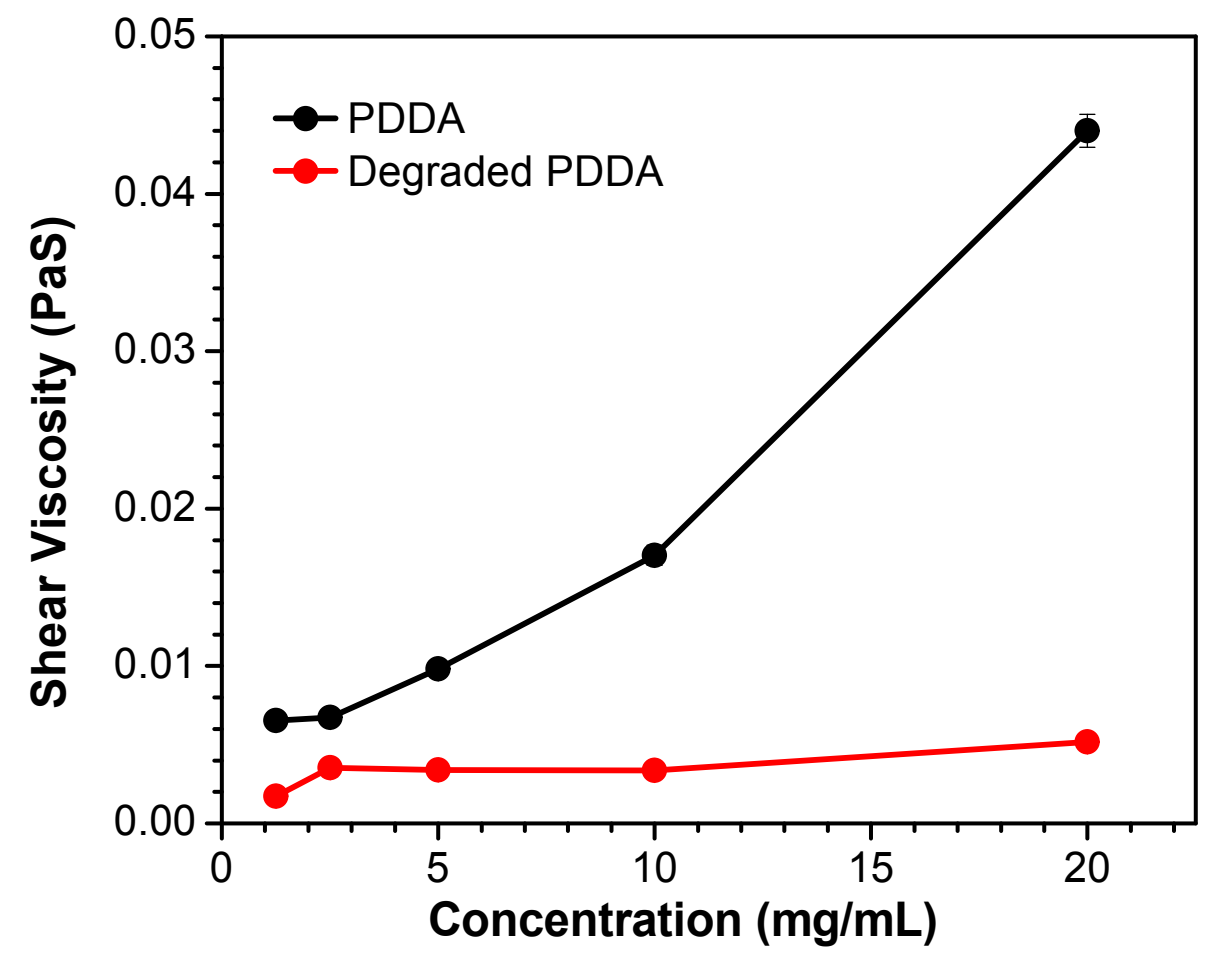

Figure S4. Shear viscosity of PDDA solutions with different concentrations before and after complete degradation in natural environment. 


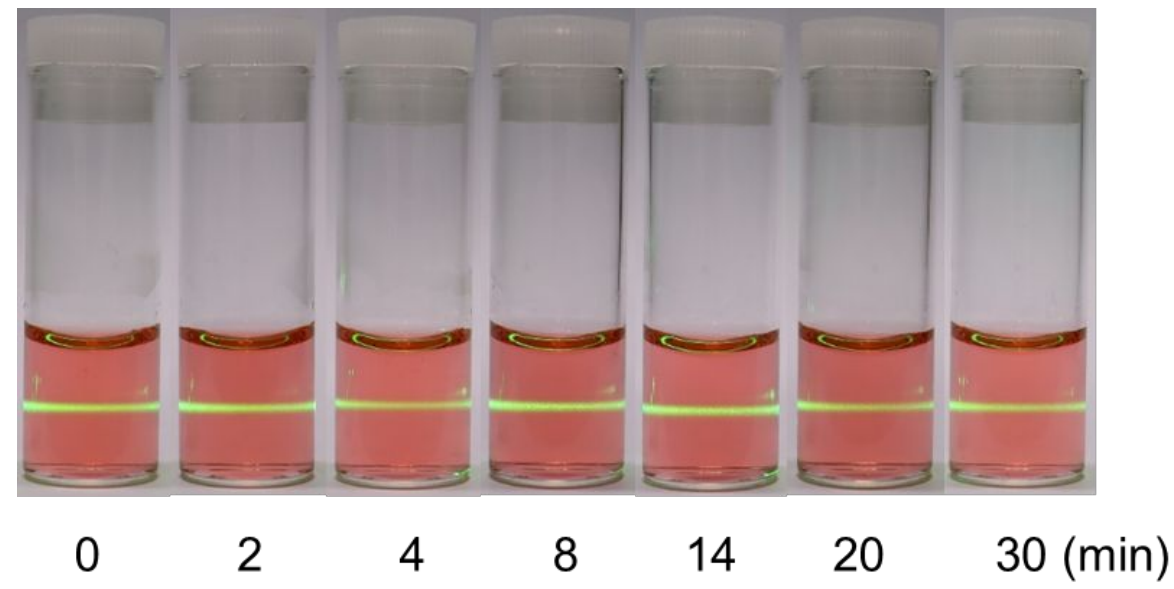

Figure S5. Photographs of a PDDA MP dispersion in deionized water kept in the dark for different time. 


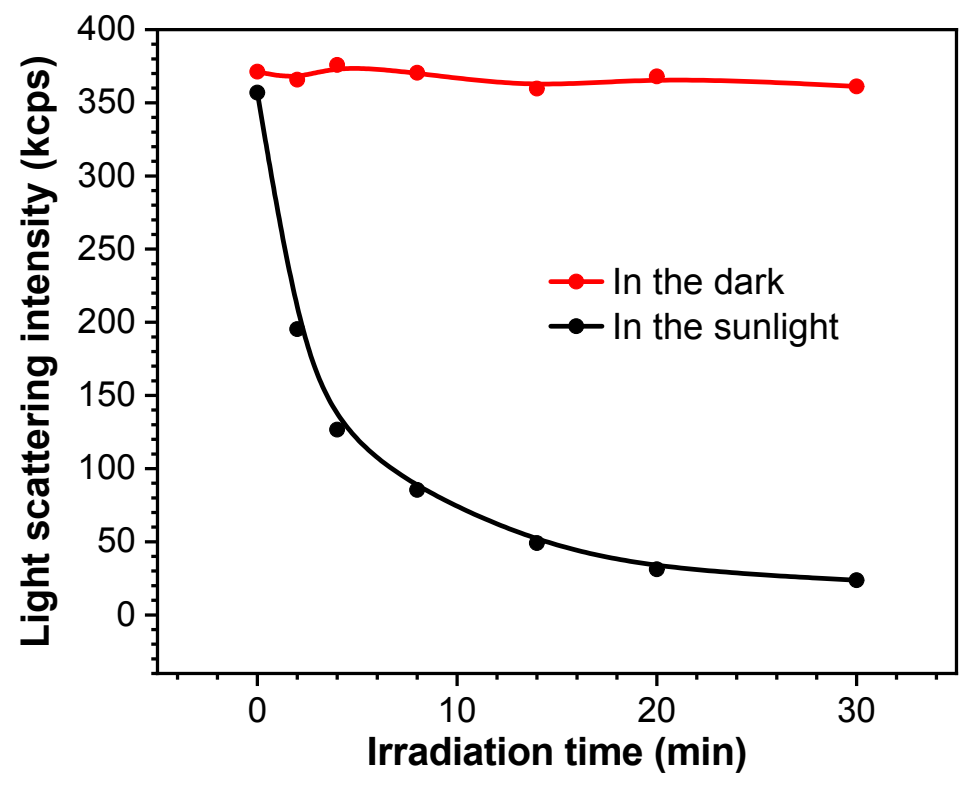

Figure S6. Light scattering intensity of the aqueous dispersions of PDDA MPs being kept in the dark or in the sunlight for different time. 


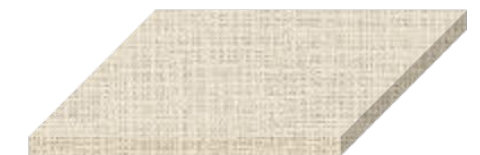

Paper substrate

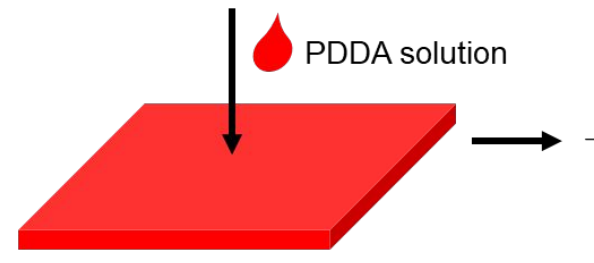

PDDA impregnated paper
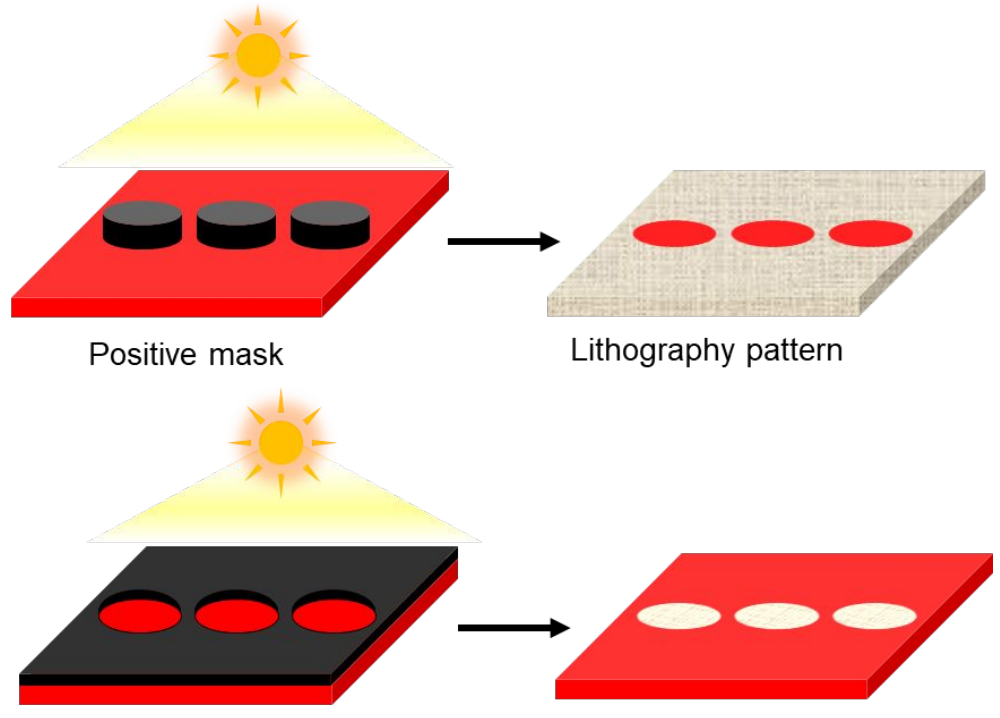

Negative mask
Lithography pattern

Figure S7. Schematic illustration of PDDA impregnated paper substrates being exposed to sunlight covered by photomasks. 


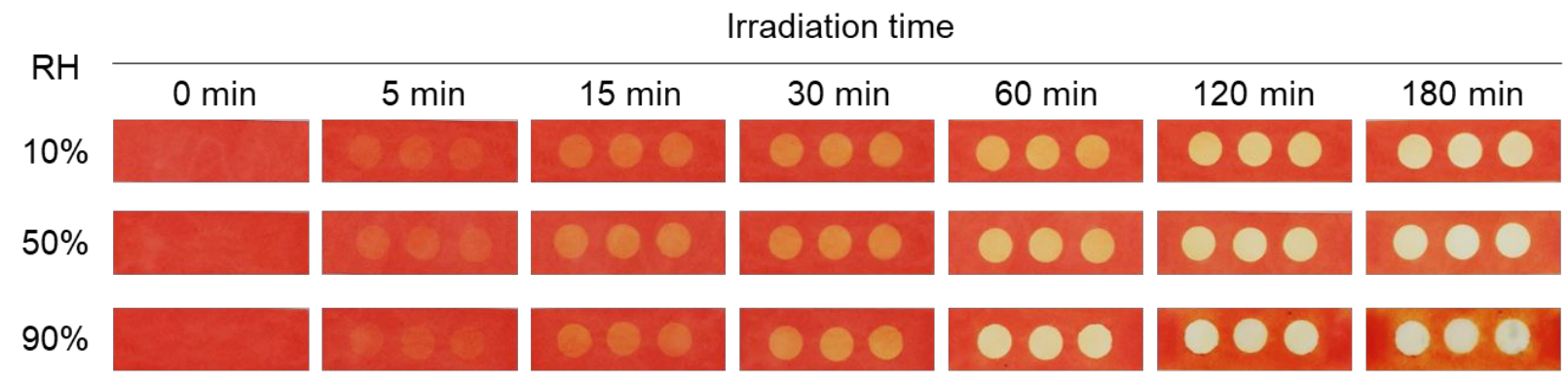

Figure S8. Time-dependent generation of negative photo patterns by sunlight-induced photolysis of PDDA films on filter papers under different humidity conditions. 

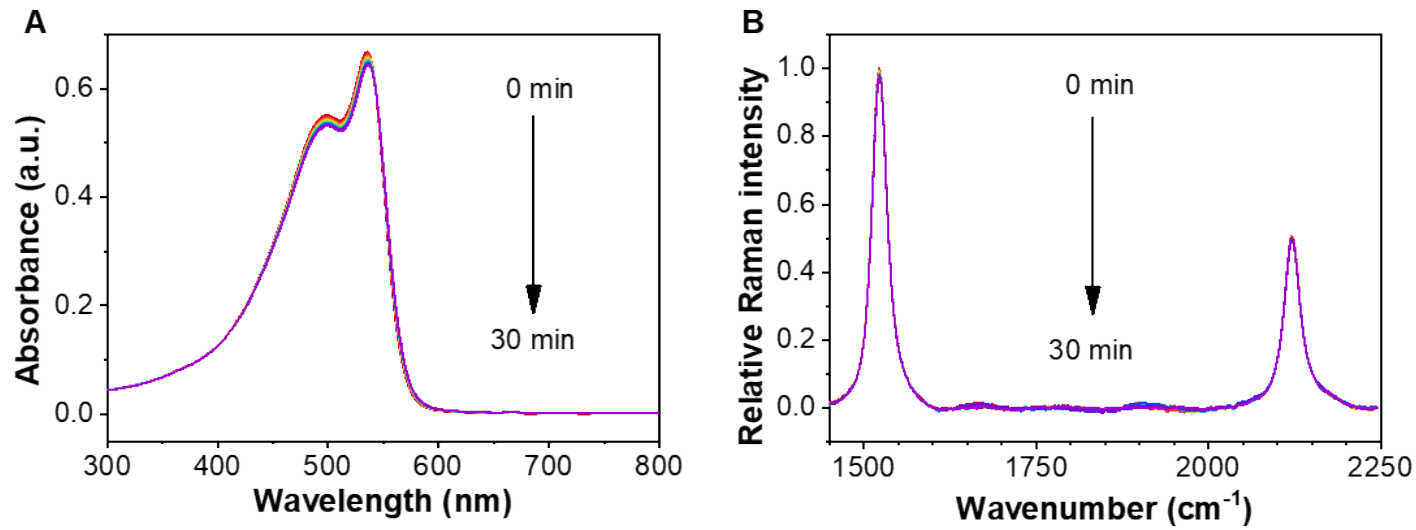

Figure S9. The UV-vis absorption (A) and Raman (B) spectra of an aqueous dispersion of PDDA MPs kept in the dark for different time. 
A

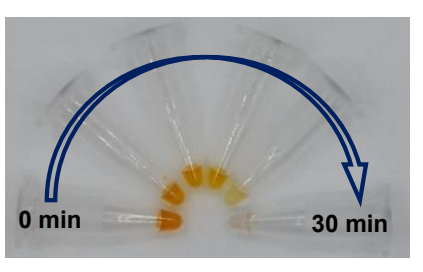

Normoxia (sunlight)

D

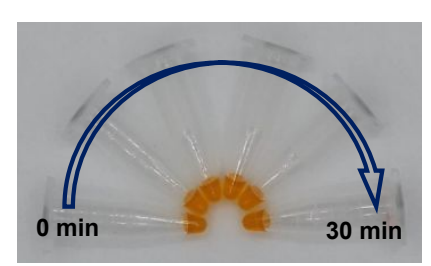

Hypoxia (dark)

G

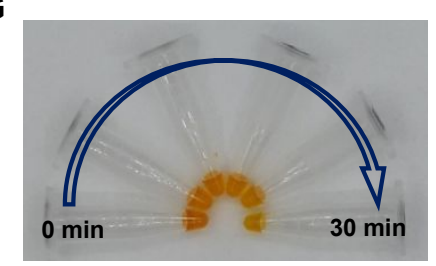

Hypoxia (sunlight)

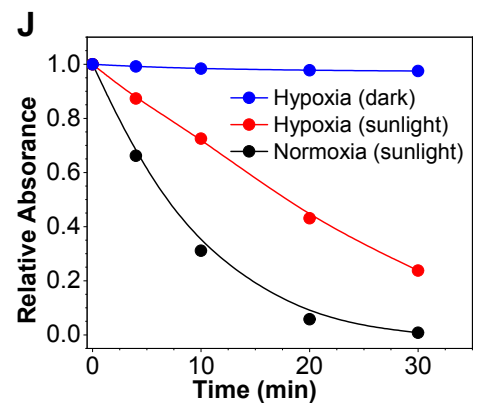

B

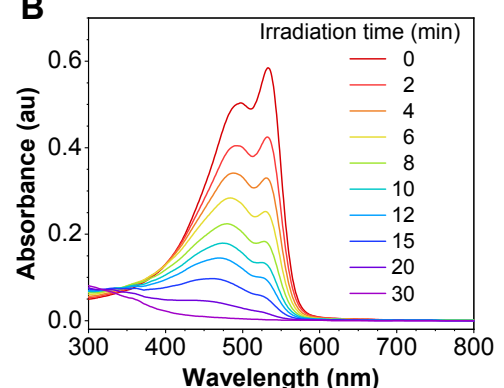

E

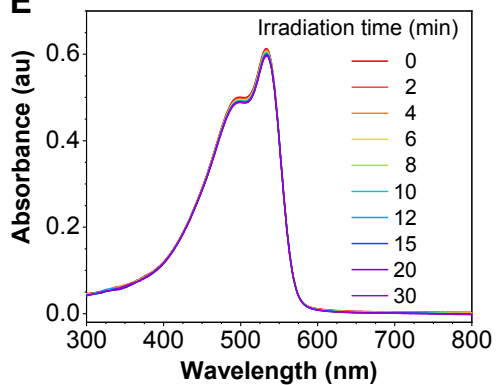

H

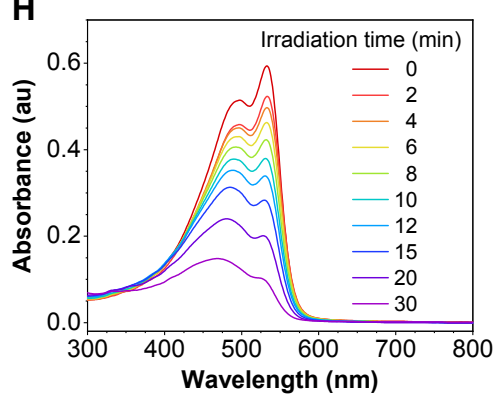

K

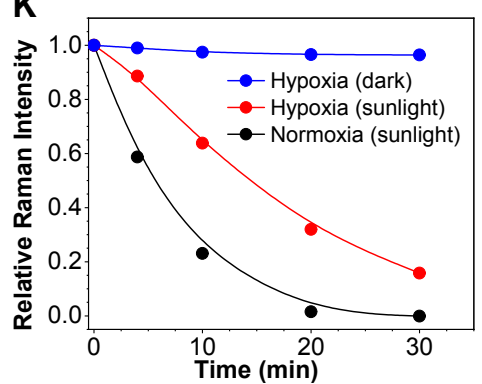

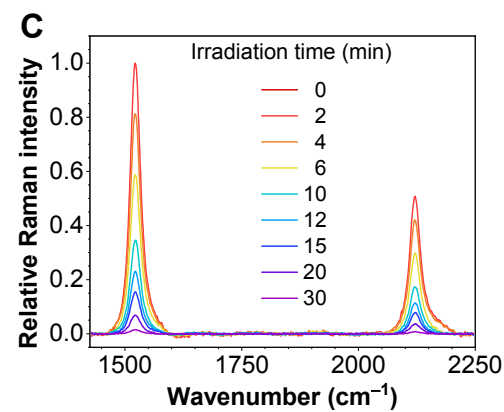
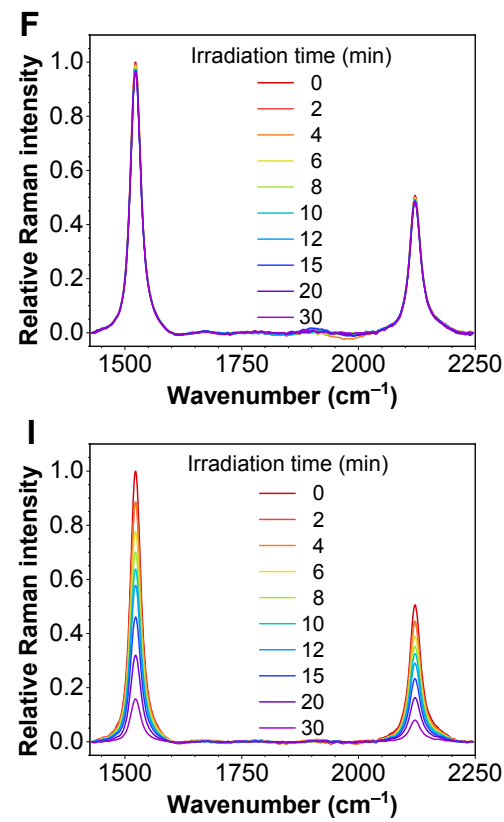

L

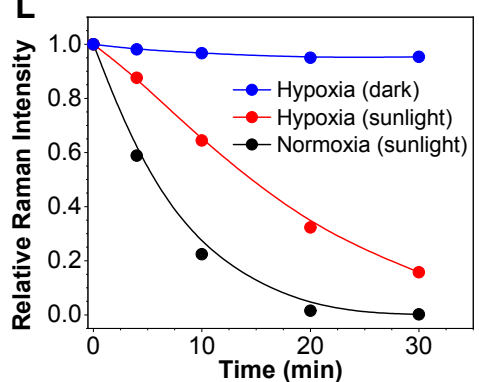

Figure S10. Stability of PDDA aqueous dispersions. (A) Photographs of aliquots of a PDDA dispersion in normoxia taken after being irradiated by sunlight for different time. (B) The absorption spectra of the PDDA dispersions in normoxia being irradiated by sunlight for different time. (C) The Raman spectra of the PDDA dispersions in normoxia being irradiated by sunlight for different time. (D) Photographs of aliquots of a PDDA dispersion in hypoxia (filled with $\mathrm{N}_{2}$ ) taken after being kept in the dark for different time. (E) The absorption spectra of the PDDA 
dispersions in hypoxia being kept in the dark for different time. (F) The Raman spectra of the PDDA dispersions in hypoxia being kept in the dark for different time. (G) Photographs of aliquots of a PDDA dispersion in hypoxia (filled with $\mathrm{N}_{2}$ ) taken after being irradiated by sunlight for different time. $(\mathrm{H})$ The absorption spectra of the PDDA dispersions in hypoxia being irradiated by sunlight for different time. (I) The Raman spectra of the PDDA dispersions in hypoxia being irradiated by sunlight for different time. (J) The relative absorbance change at $500 \mathrm{~nm}$ of PDDA dispersions in different conditions as a function of time. (K) The relative Raman intensity change at $1520 \mathrm{~cm}^{-1}$ of PDDA dispersions in different conditions as a function of time. (L) The relative Raman intensity change at $2120 \mathrm{~cm}^{-1}$ of PDDA dispersions in different conditions as a function of time. 
Table S1. HPLC-MS analysis of crude PDDA degradation products upon sunlight irradiation: Retention time, $\mathrm{m} / \mathrm{z}\left(\mathrm{M}^{-}\right)$, chemical formula calculated based on high resolution $\mathrm{m} / \mathrm{z}\left(\mathrm{M}^{-}\right)$, relative intensity of corresponding peaks on HPLC, and proposed chemical structure of each formula inferred.

\begin{tabular}{|c|c|c|c|c|}
\hline $\begin{array}{l}\text { Retention time } \\
\text { (min) }\end{array}$ & $\mathrm{m} / \mathrm{z}\left(\mathrm{M}^{-}\right)$ & Formula & $\begin{array}{c}\text { Relative intensity } \\
(\%)\end{array}$ & Possible structure \\
\hline 7.24 & 133.0130 & $\mathrm{C}_{4} \mathrm{H}_{6} \mathrm{O}_{5}$ & 6.16 & \\
\hline 8.05 & 103.0023 & $\mathrm{C}_{3} \mathrm{H}_{4} \mathrm{O}_{4}$ & 2.68 & \\
\hline 8.92 & 147.0287 & $\mathrm{C}_{5} \mathrm{H}_{8} \mathrm{O}_{5}$ & 2.94 & \\
\hline 12.47 & 117.0180 & $\mathrm{C}_{4} \mathrm{H}_{6} \mathrm{O}_{4}$ & 59.14 & \\
\hline 16.24 & 275.0407 & $\mathrm{C}_{10} \mathrm{H}_{12} \mathrm{O}_{9}$ & 0.15 & \\
\hline 19.31 & 259.0457 & $\mathrm{C}_{10} \mathrm{H}_{12} \mathrm{O}_{8}$ & 0.07 & \\
\hline 34.75 & 257.0299 & $\mathrm{C}_{10} \mathrm{H}_{10} \mathrm{O}_{8}$ & 10.15 & \\
\hline 35.62 & 187.0603 & $\mathrm{C}_{8} \mathrm{H}_{12} \mathrm{O}_{5}$ & 9.91 & \\
\hline 37.92 & 153.0545 & $\mathrm{C}_{8} \mathrm{H}_{10} \mathrm{O}_{3}$ & 8.81 & \\
\hline
\end{tabular}




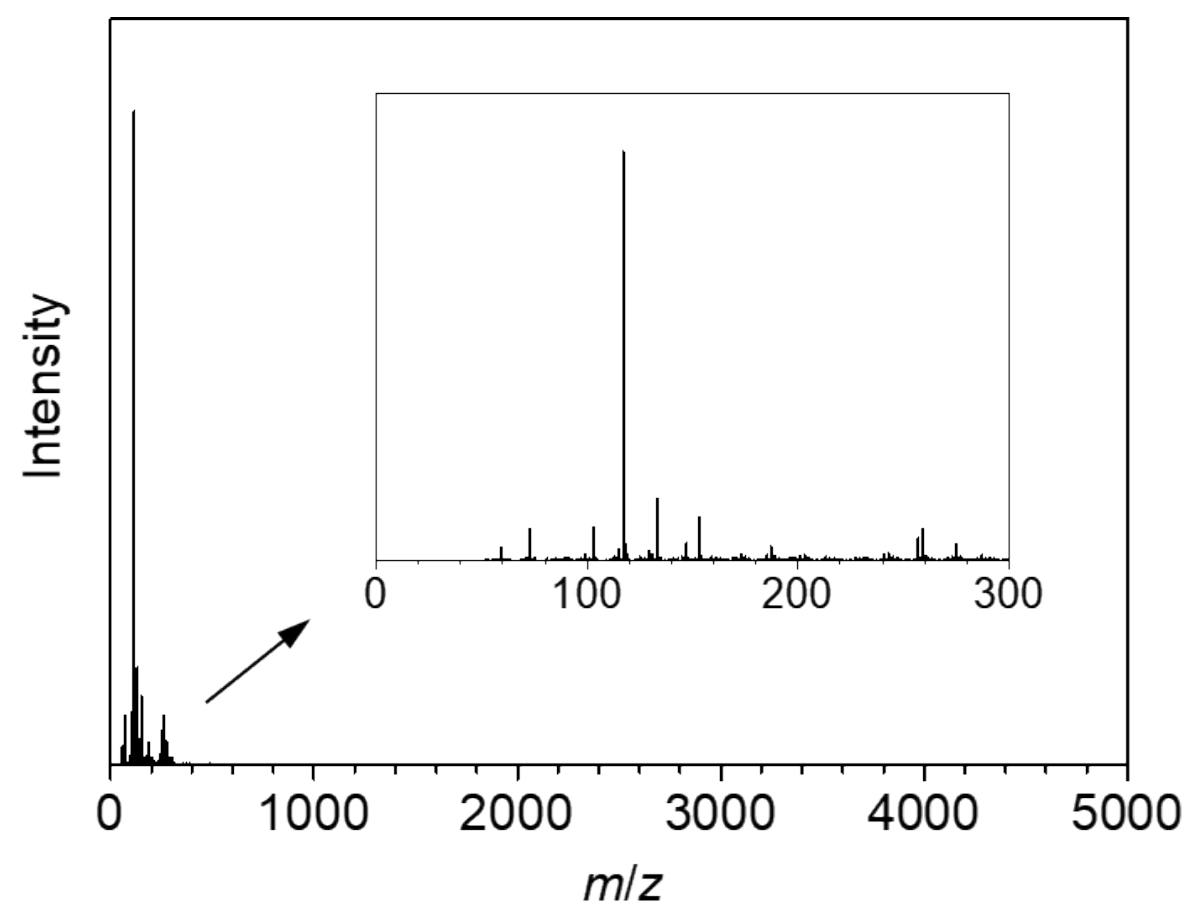

Figure S11. HR-MS of crude PDDA degradation products upon sunlight irradiation. 

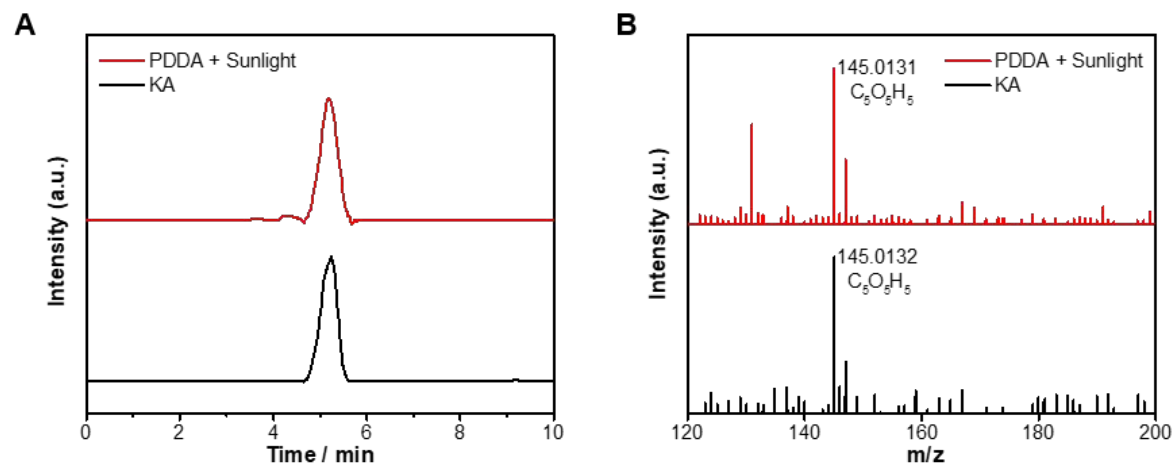

Figure S12. Detection of the intermediate product of PDDA degradation process upon sunlight irradiation and 2-ketoglutaric acid (KA) standard by HPLC-MS with an ion detector. (A) HPLC analysis of ion count of $145.0132\left(\mathrm{M}^{-}\right)$from crude PDDA degradation products upon sunlight irradiation. The standard 2-ketoglutaric acid was used as a reference. (B) Mass spectrum of the ingredients collected from HPLC at $5.22 \mathrm{~min}$. The standard 2-ketoglutaric acid was used as a reference. 

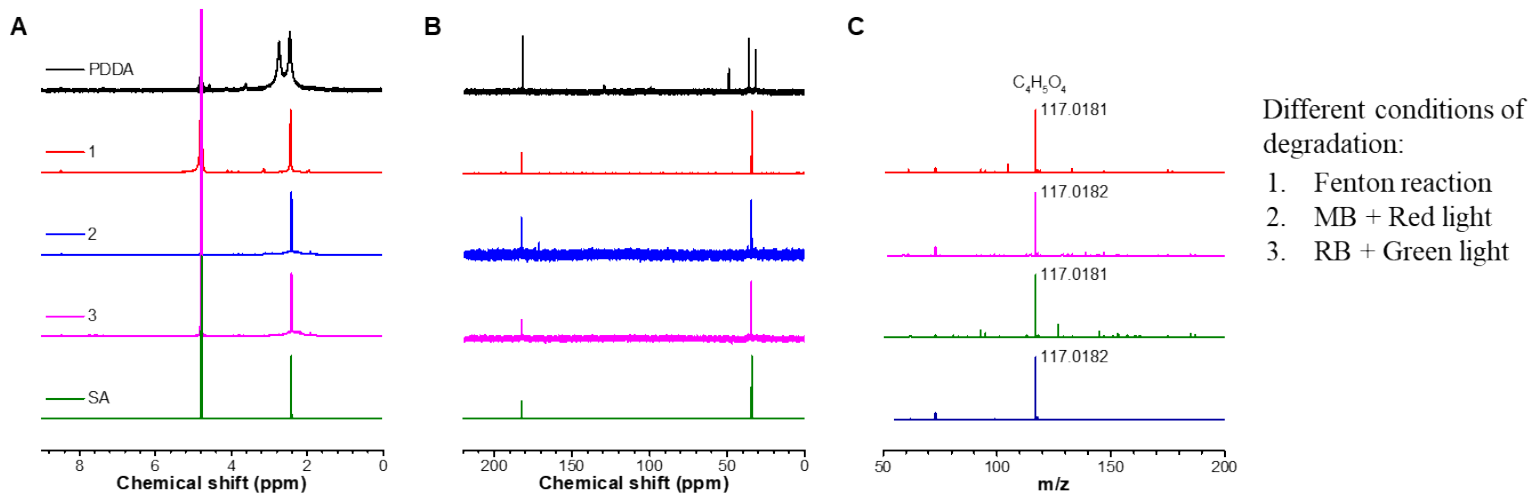

Figure S13. ${ }^{1} \mathrm{H}$ NMR spectra (A) and ${ }^{13} \mathrm{C}$ NMR spectra (B) of pristine PDDA and crude PDDA degradation mixture under three different degradation conditions (shown on the right) and the standard succinic acid. (C) HR-MS of crude PDDA degradation mixture under three different degradation conditions (shown on the right) and the standard succinic acid. 
Table S2. The concentrations of total organic carbon composition in a PDDA solution before and after sunlight irradiation

\begin{tabular}{cc}
\hline Before degradation & After degradation \\
\hline $10.04 \mathrm{mg} \mathrm{L}^{-1}$ & $7.87 \mathrm{mg} \mathrm{L}^{-1}$ \\
\hline
\end{tabular}




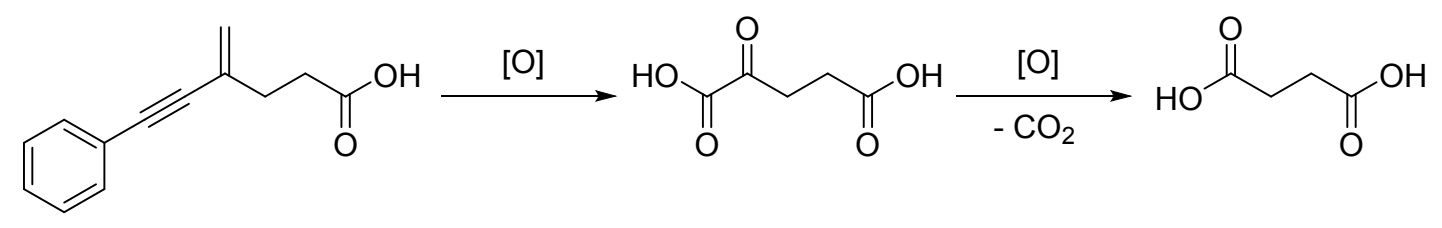

Scheme S1. The degradation reaction of the model compound mediated by reactive oxygen species. 


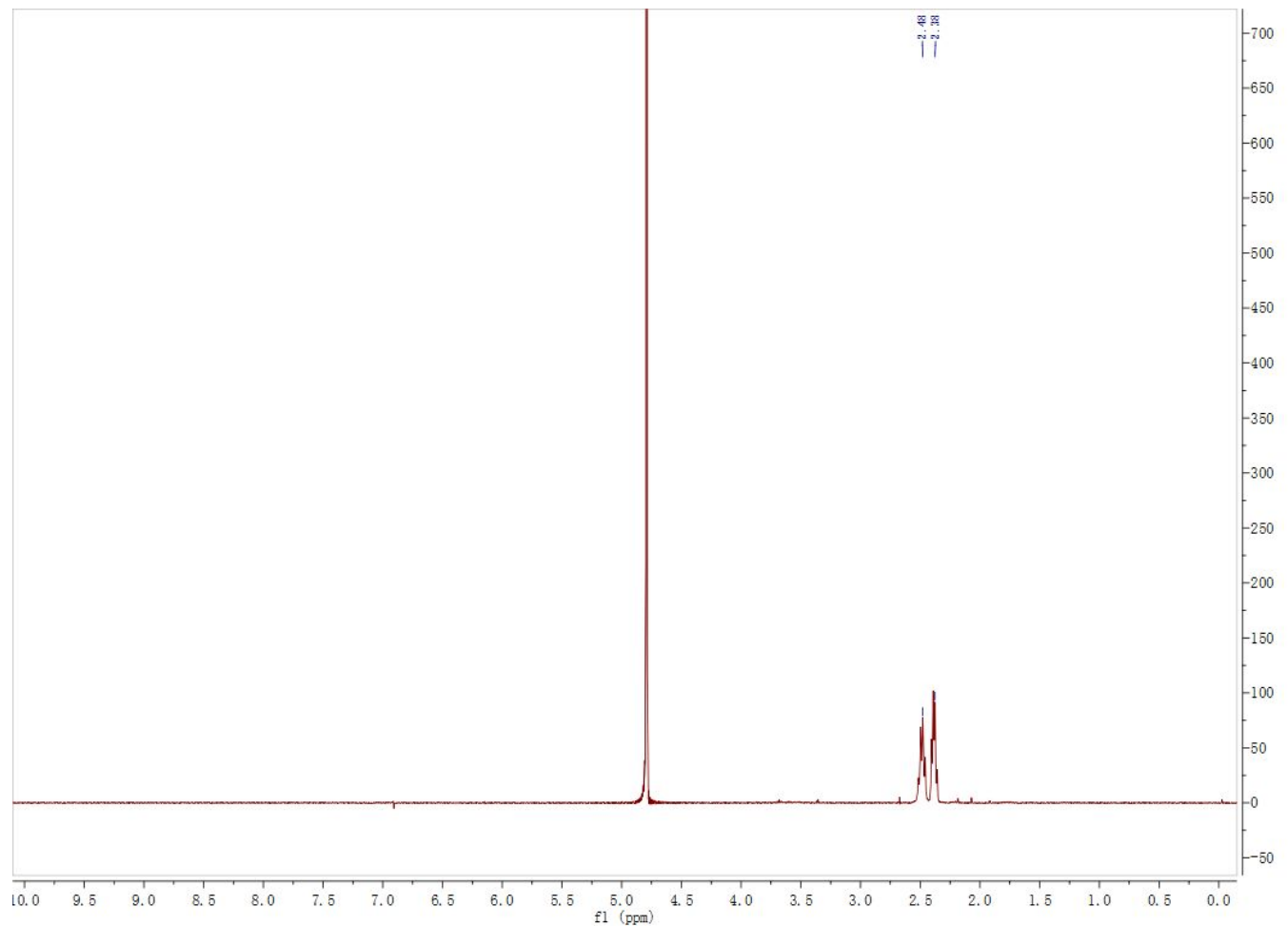

Figure S14. ${ }^{1} \mathrm{H}$ NMR spectrum of 4-pentyn-1-ol- ${ }^{13} \mathrm{C}_{2}$ in $\mathrm{D}_{2} \mathrm{O}$. 


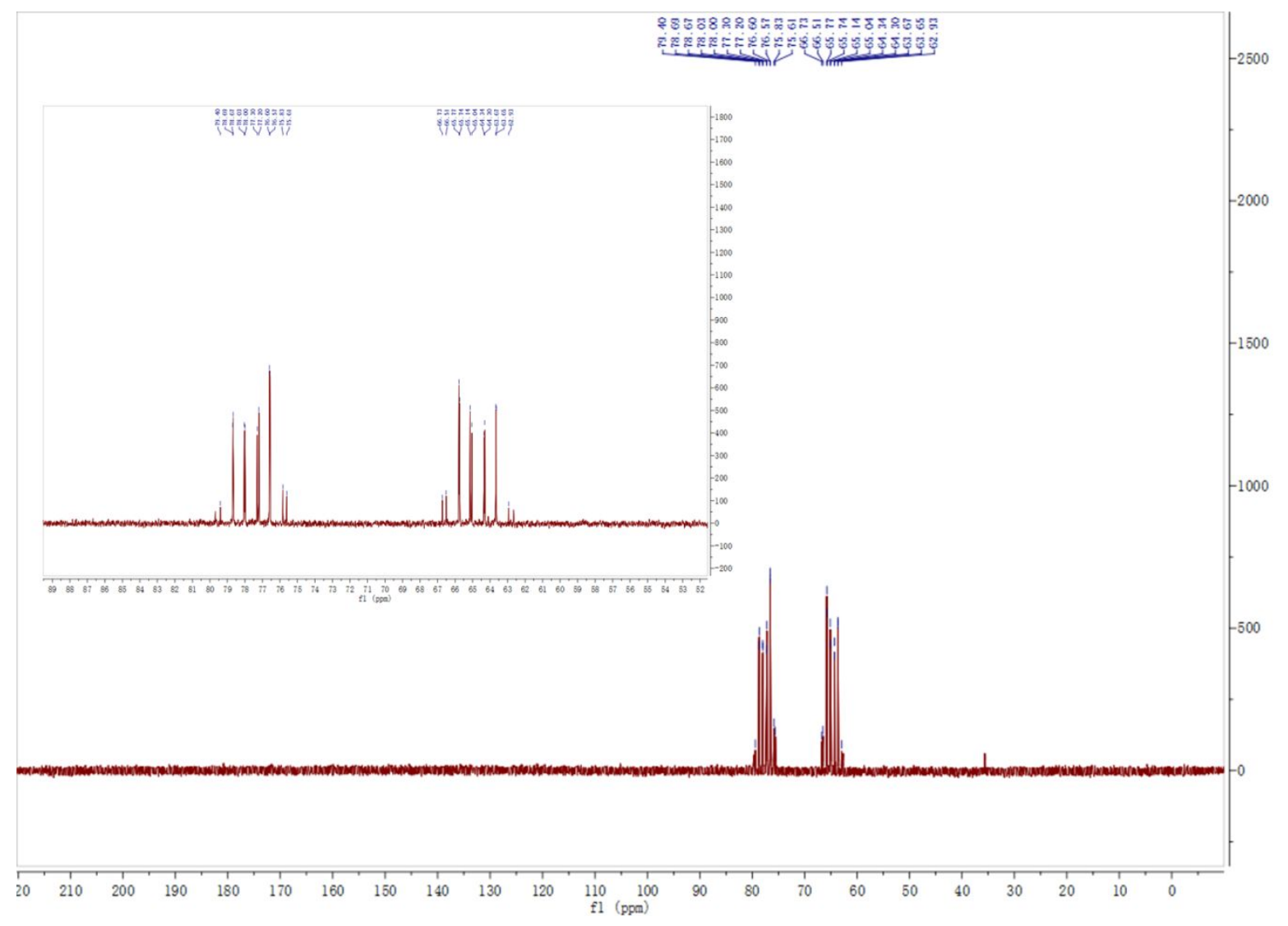

Figure S15. ${ }^{13} \mathrm{C}$ NMR spectrum of 4-pentyn-1-ol- ${ }^{13} \mathrm{C}_{2}$ in $\mathrm{D}_{2} \mathrm{O}$. 


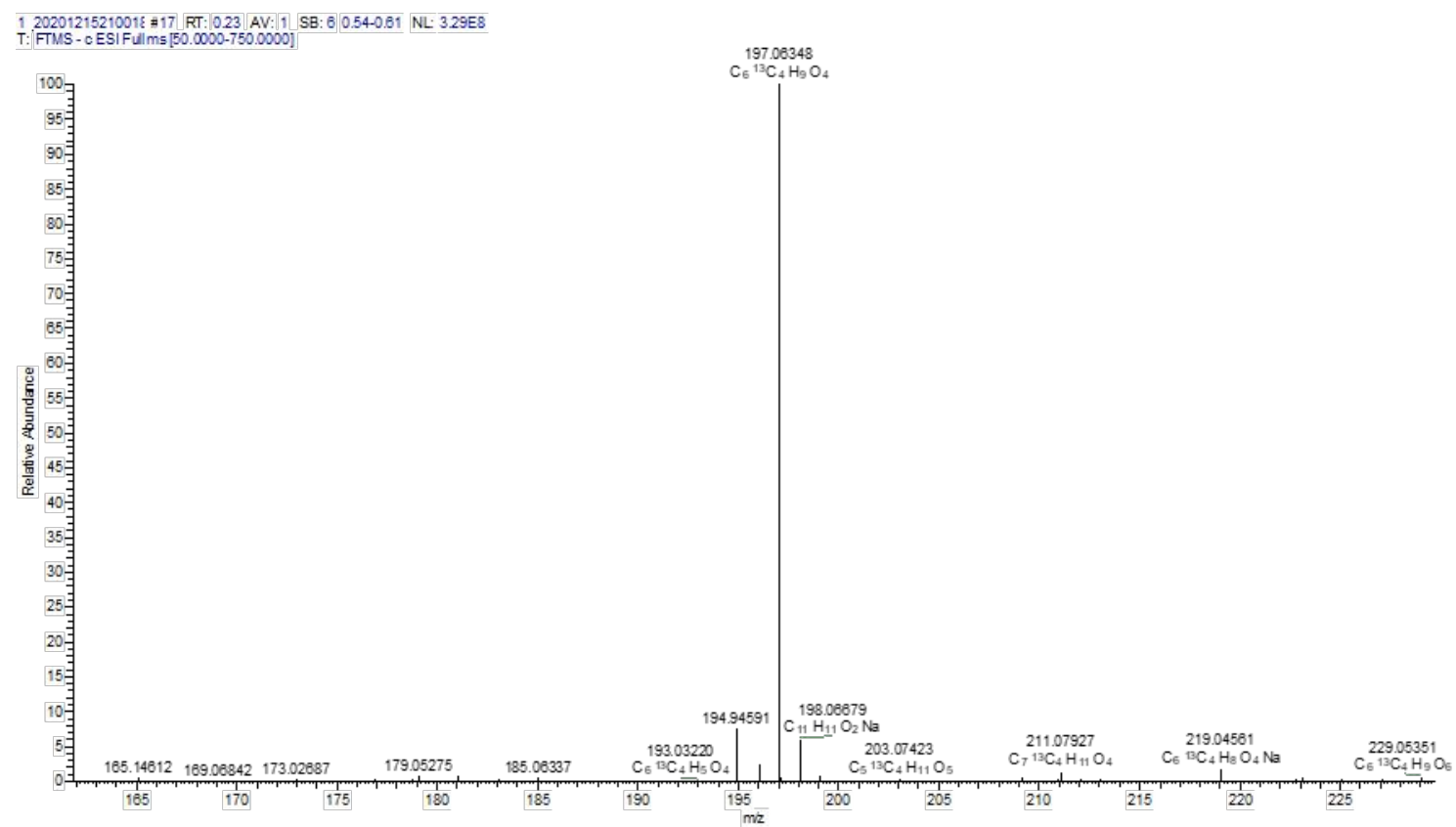

Figure S16. HRMS spectrum of 4-pentyn-1-ol- ${ }^{13} \mathrm{C}_{2}$ (Anion mode $\left.[\mathrm{M}-\mathrm{H}]^{-}\right)$. 


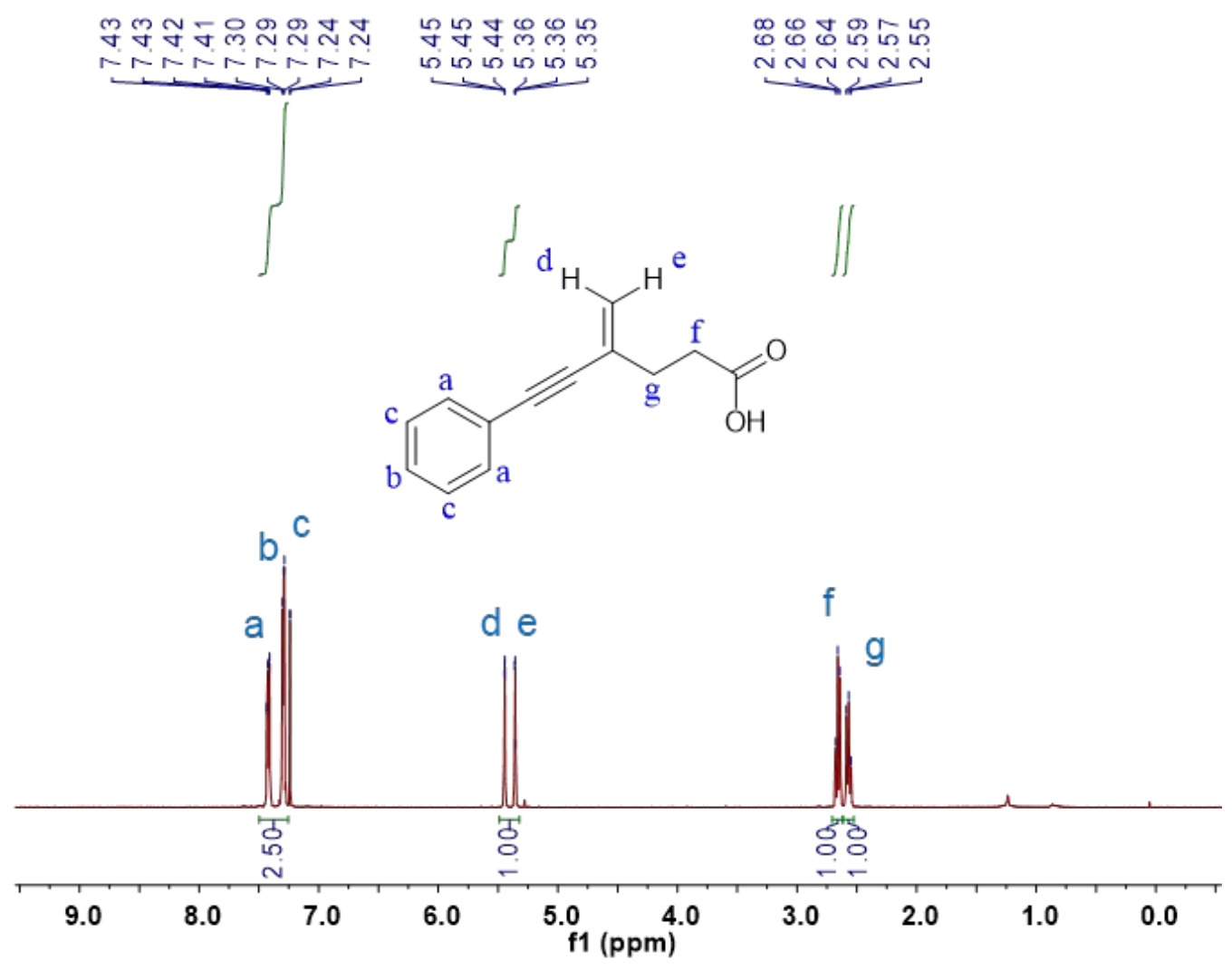

Figure S17. ${ }^{1} \mathrm{H}$ NMR spectrum of 4-phenylpent-4-enoic acid in $\mathrm{CDCl}_{3}$. 


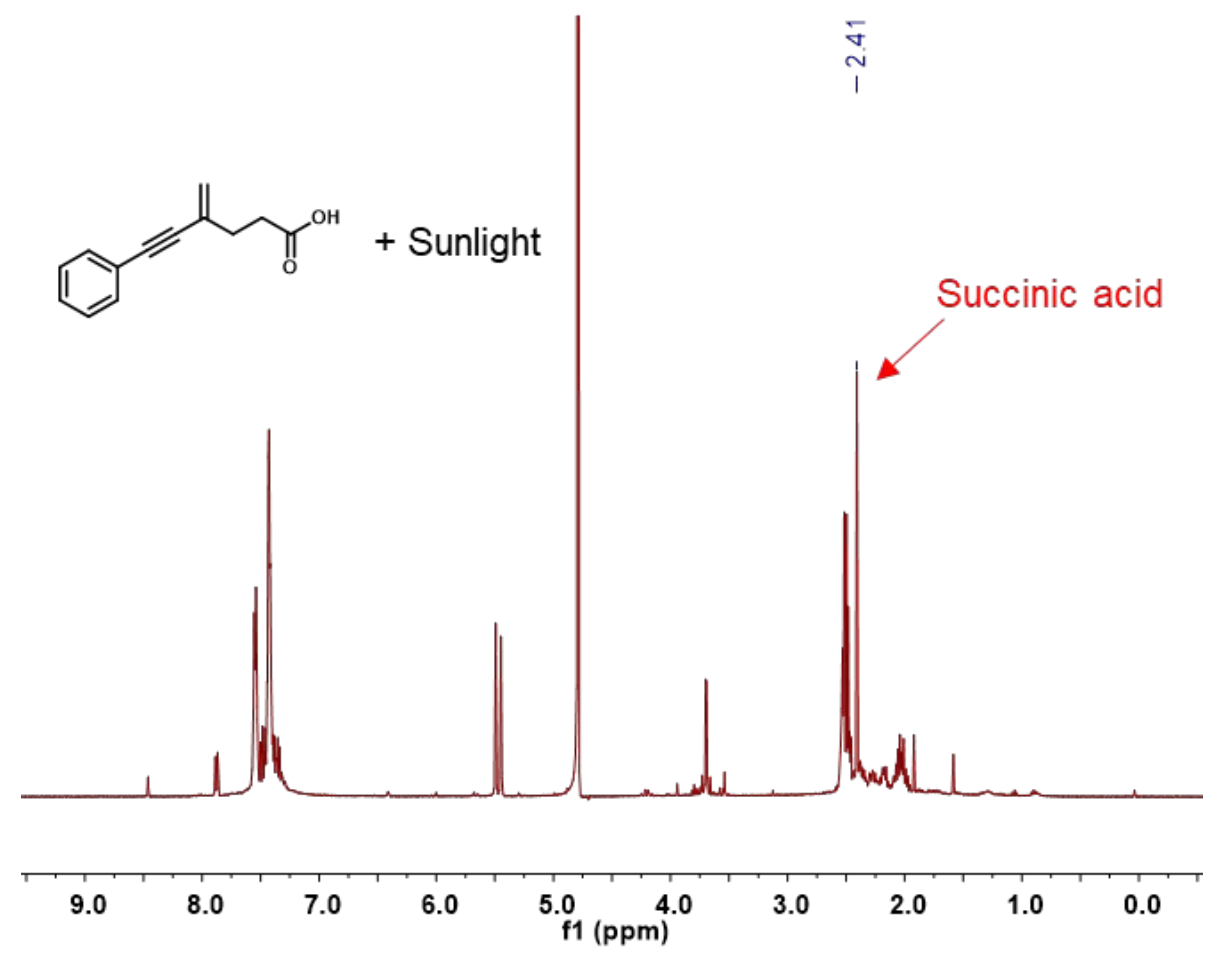

Figure S18. ${ }^{1} \mathrm{H}$ NMR spectrum of the crude degradation products of the model compound upon sunlight irradiation. 


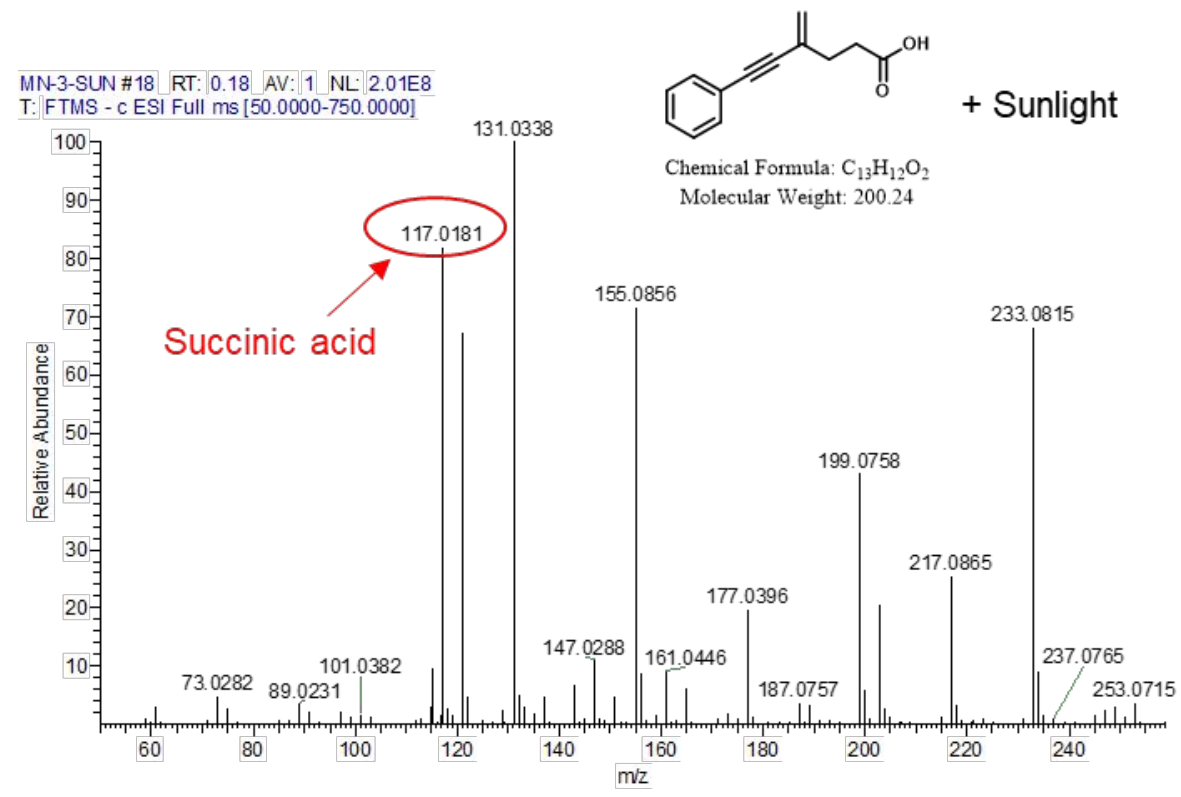

Figure S19. HRMS spectrum of the crude degradation products of the model compound upon sunlight irradiation. 


\section{References}

1. Tian, S.; Li, H.; Li, Z.; Tang, H.; Yin, M.; Chen, Y.; Wang, S.; Gao, Y.; Yang, X.; Meng, F.; Lauher, J. W.; Wang, P.; Luo, L. Polydiacetylene-based ultrastrong bioorthogonal Raman probes for targeted live-cell Raman imaging. Nat. Commun. 2020, 11 (1), 81.

2. Stefani, H. A.; Cardoso, L. D. G.; Valduga, C. J.; Zeni, G. Study of the Regioselectivity in the Hydrotelluration of Hydroxy Alkynes. Phosphorus, Sulfur, and Silicon and the Related Elements 2001, 172 (1), 167-172.

3. Alazet, S.; Le Vaillant, F.; Nicolai, S.; Courant, T.; Waser, J. Divergent Access to $(1,1)$ and (1,2)-Azidolactones from Alkenes using Hypervalent Iodine Reagents. Chem. - Eur. J. 2017, 23 (40), 9501-9504. 